\title{
The Relationship between EFL Teachers' Critical Thinking and Use of Motivational Strategies
}

\author{
Gholamreza Parsi \\ Islamic Azad University Central Tehran Branch, Iran \\ E-mail: parsi.gh862@gmail.com
}

Doi:10.7575/aiac.alls.v.8n.2p.14

Received: 10/01/2017

URL: http://dx.doi.org/10.7575/aiac.alls.v.8n.2p.14

Accepted: 22/02/2017

\begin{abstract}
The present study was conducted to investigate the relationship between EFL teachers' critical thinking and use of motivational strategies. The participants of this study were 101 EFL teachers. These teachers were both male and female between 21 to 36 years old, and they taught intermediate and advanced levels and varied in their experience from 3 to 17 years. They were chosen randomly from private language schools in Mashhad and two questionnaires were given to them: A questionnaire to evaluate the use of motivational strategies (Cheng and Dornyei, 2007) and another questionnaire to estimate their critical thinking (Honey, 2000).To fulfill the objective of the study, a Spearman Rank Order Correlational analysis was conducted to investigate any significant relationship between the two variables. The results showed that there is no correlation between critical thinking and motivational strategies. This result may help teacher educators to consider the relationship of critical thinking and teachers' use of motivational strategies as an integral part of the teaching and learning process in teacher training courses.
\end{abstract}

Keywords: Critical Thinking, Use of Motivational Strategies, EFL teachers

\section{Introduction}

In the last few decades, due to the advance of the digital world, there has been a gradual but significant emphasis on adults' critical thinking in the context of education. Critical thinking gains its importance partly because the adults who want to live, work and function adequately in the world that changes rapidly, have to enhance their skills in order to generate valuable and creative ideas. These skills are referred to a concept which is known as critical thinking (Ennis, 1996). Hence, in order to discover new paths for solving problems, raising questions and relating previous knowledge to the new ones, they have to think critically in this computerized age.

There are different views of critical thinking. As Mason (2007) maintains, many philosophers have advanced theories of critical thinking. Some, like Ennis (1996), assert that critical thinking contains particular skills, such as existence able to assess reasons appropriately, or to identify false quarrels. According to Siegel (1990), critical thinking is a critical viewpoint or character for example the disposition to ask investigating questions, or critical orientation.

As pointed out by Astleitner (2007), critical thinking is a higher-order thinking skill which includes evaluating arguments, and is a purposeful, self-regulatory judgment which ends in interpretation, analysis, evaluation, and inference.

In other words, critical thinking, as described by Marzano, Pickering and Pollack (2001), contends reflective thinking that is focused on understanding an issue, creating and weighing solutions, and making informed decisions. It is one of the objectives of education that students obtain critical thinking skills enabling easy access to knowledge and overcoming challenges more easily.

Nowadays, many teachers have disregarded the fact that teachers' use of motivational strategies can have a significant effect on their process of teaching in their classrooms (Huangfu, 2012). Many scholars and many studies had emphasized the significant effect of teachers' motivational strategies to enhance critical thinking in the educational context (e.g., Alison \& Halliwell, 2002; Brown, 2001; Chambers, 1999; Williams \& Burden, 1997). The nature to think critically has been explained as the "consistent internal motivation to engage problems and make decisions by using critical thinking" (Facione, 2000, p. 65).

Motivational strategies have been defined as "those motivational influences that are consciously exerted to achieve some systematic and enduring positive effect" (Dornyei, 2001, p.28). On the other hand, Chaung (2001) suggested that teachers must utilize popular culture in their educational settings in order to enhance motivation. By contrast, some scholars advocated teachers' motivational strategies, which are related to a large numbers of classroom's microstrategies. Thansoulas (2002), developed a four sub-categories for teachers' motivational strategies by utilizing Dörnyei and Ottos (1981) process-oriented model.

The researcher in this study intended to explore whether these two concepts are related in some ways or not, so that new ways for teachers might be conceivable to analyze and solve problems. To the best of the researcher's knowledge and 
based on the extensive review of the related literature, few studies, if any at all, have been conducted on the aforementioned variables. Thus, this study aimed to fill the research gap by systematically investigate the possible relationship between EFL teachers' use of motivational strategies and critical thinking.

\section{Review of the Related Literature}

\subsection{Critical Thinking}

Throughout the last few decades, several definitions have been presented for critical thinking, however there is no consensus on the definition critical thinking. As pointed out by Kadir (2007), this lack of agreement in defining the concept of critical thinking is associated with different philosophical and psychological viewpoints. In fact, theorists focus on the concept of critical thinking, whereas psychologists mainly focus on the concept of critical thinking abilities.

Critical thinking has been defined by Noddlings (2006) as the use of rationale in a diligent and clever way on personal behavior, decision making and belief that are matters of social or moral significance, while Cottrell (2005) sees the concept of critical thinking as a cognitive activity integrated with mind usage. According to Paul, Elder and Bartell (1997), the rational origins of critical thinking go back to the instruction practice and vision of Socrates for more 25 centuries ago. In the current century, the robust necessity for critical thinking in education and life was recognized. At the present time, the significance of critical thinking and its influence have become ever more apparent.

King (1995) states that the distinguishing aspect of those who are critical thinkers is having an analytical mind; thus, good critical thinkers are essentially those who probe good inquiries. Paul, Elder and Bartell (1997) uphold that selfassessment is a central issue to critical thinking, and merely those learners who learn to measure their own thinking are truly regarded as critical thinkers. Furthermore, Paul and Elder (2002) maintain that improving critical thinking is a progressive procedure which necessitates heavy labor, and becoming an brilliant thinker is not conceivable by merely taking a beginning course. Consequently, the critical features of a critical thinker request a long-term period of improvement.

In the same vein, Kurffiss (1988) believes that critical thinking is "the ability to make sound judgments in complex, real-world situations, based on available evidence and a clearly worked out value system" (p.6). Besides, Ennis (1985) defines critical thinking as "reasonable and reflective thinking focused on deciding what to believe or do" (p.45).

Furthermore, Glaser (1942) maintains that "critical thinking is a persistent effort to examine any belief or supposed form of knowledge, the light of evidence that supports it and the further conclusions to which it tends" (p.13). He continues by asserting that critical thinking is "the ability to focus on reasonable and reflective thinking" (p.13). In Glaser's point of view critical thinking empowers the learners to generously express their own thoughts, to exhibit the interrelationships among their attitudes, and to produce higher levels of thinking.

Norris and Ennis (1989) argue that idyllic critical thinkers are able to: (1) Focus on a question, (2) Analyze arguments, (3) Ask and answer clarification and/or challenging questions, (4) Read and use graphs and math, (5) Judge the credibility of a source, (6) Observe; judge observation reports, (7) Deduce; judge deductions, (8) Make; judge material inferences: (a) Enumerative induction, (b) Argument to best explanation. (9) Make and judge value judgments, (10) Define terms; judge definitions; handle equivocation, (11) Attribute unstated assumptions; judge such attributions, (12) Think suppositionally, (13) Integrate one's dispositions and abilities, (14) Proceed in an orderly manner appropriate to the situation, (15) Employ, recognize, and appropriately react to rhetorical strategies and "fallacy" labels.

\subsection{Motivational Strategies}

As argued by Ellis (1997) motivation primarily comprises the affective states and attitudes that affect thoroughly the degree of students' effort to learn a second or foreign language. Motivation is regard as being remarkably complex; according to McDonough (2007), motivation is regarded as a property of the student, however is regarded as a transitive notion: teachers and instructors can motivate their students; motivation is dynamic and alters throughout time particularly in the process of long term learning.

As motivation is one of the crucial factors which identify success in second language learning, strategies for motivating the learners should be considered as a key feature of the theoretical analysis of second language motivation. Nonetheless, by watching at the literature it can be discovered that more investigation has been performed on recognizing and examining different motives and authenticating motivational philosophies than on offering methods to enhance motivation.

The instructor's motivational strategy has been underlined as a main field of second language motivational research, due to the fact that teacher's motivational strategy has an important relation with learner's second language motivation (Dornyei, 2010). Additionally, previous investigations have indicated that when second language students are motivated, it significantly positively effects their second language achievement.

As Ushioda (2011) maintains learners' lack of motivation is an important problem for language teachers in numerous situations all around the world. Therefore, a challenging responsibility for researchers of second language motivation is assisting teachers to find ways of provoking, increasing, and maintaining learners' motivation (Dornyei, 2010).

Strategies for increasing motivation in the language learning contexts are located at the crossing point of second language motivation investigation and classroom practice. No solo motivational strategy is able to always motivate every student in all the situations due to the fact that classroom context is a place with high dynamicity. The efficiency 
of a strategy is the consequence of the dealings between assemblages of contextual variables, some of which are most likely culture-specific, and some are culture-neutral.

Variables of this kind comprise approaches to teaching and learning, discrete students and teachers' personality features, affective states educational ideology, and the composition of the learner group (Dornyei \& Csizer, 1998). It is also believed that, dissimilar learning contexts might either increase or nullify the efficiency of some strategies, but investigation is required to highlight these contexts.

Only a few empirical studies have been conducted on motivational strategy use. For instance, Solak, and Bayar (2014) conducted a study in order to scrutinize the variables affecting the motivational strategies applied by non-native EFL teachers in Turkey. For this purpose, 122 non-native EFL teachers and instructors took part in their study by completing the "Motivational Strategies Questionnaire" primarily developed by Cheng and Dornyei (2007).

Having collected the required data, the appropriate statistical analyses were run. The results of their investigation revealed that EFL teachers and instructors applied each motivational strategy more than the average and also there no significant difference was found between EFL teachers' and instructors' motivational strategy use and their years of teaching experience. Moreover the findings of their investigation revealed no significant difference between motivational strategy use of EFL teachers and instructors and gender, the state of presence abroad and the sort of institute of served.

Likewise, Al-Mahrooqi, Abrar-ul-Hassan and Asante (2012) conducted a research study in order to examine the significance that EFL teachers and instructors attach to the application of particular strategies for motivating their learners to learn English. Moreover, their investigation aimed at establishing how often EFL teachers and instructors use motivational strategies in their actual teaching practice. Moreover, it is worth mentioning that their research study was a large scale project which was a nationwide survey. The researchers of the study stated that their investigation was a 'modified replication' of Cheng and Dornyei's (2007) investigation. In doing so, 286 EFL teachers and instructors took part in the study by rating the 48 motivational strategies according to significance and the frequency with which they applied the motivational strategies in their own teaching and instruction contexts.

The results of the study were analyzed with regard to the least and most significant motivational strategies, those most infrequently and frequently used, and the association between significance and frequency of use. The findings of their study showed that EFL teachers and instructors in Oman devastatingly certify the use of all the 48 motivational strategies mentioned in the questionnaire. Additionally, the results indicated that the most preferred motivational strategies among the EFL teachers and instructors were associated with the participants' personal performance in their own classrooms.

Finally, Takeuchi and Sugita (2010) conducted an empirical study with regard to motivational strategies in EFL classrooms at the secondary school level. The researchers described the teachers' authentic employment of 15 motivational strategies on the ground of self-described frequency data throughout a period of two-month. Moreover, the associations among the frequency of the 15 motivational strategies and the power of learners' motivation were also examined. The results of data analysis indicated that teachers made use of the motivational strategies in many different ways and only some of the motivational strategies had a significant relationship with learners' motivation. Besides, it was also revealed that the efficiency of some of the strategies differed based on learners' English proficiency level.

\subsection{Research Question}

The present study was conducted in order to seek answer to the following question:

1. Is there any significant relationship between EFL teachers' use of motivational strategies and critical thinking? It is noteworthy that a null hypothesis was assumed for the aforementioned research question.

\section{Method}

\subsection{Participants}

The participants of this study were 101 EFL teachers. These teachers were between 21 to 36 years old, and they taught intermediate and advance levels and varied in their experience from 3 to 17 years (male and female). All of them were non-native speakers. They were chosen through convenient sampling from different private language schools (e.g., Danesh, Golestan, and Kish Air) in Mashhad.

\subsection{Instrumentation}

\subsubsection{Critical Thinking Questionnaire}

The English version of Peter Honey's (2000) CTQ was used to assess the participants' critical thinking. It contains 30 five-point likert scaled items exploring what a person might do or might not do when they think critically about a subject. It was administered to the participants to evaluate the three macro skills of comprehension (10 Items), analysis (10 Items) and evaluation (10 Items). As pointed out by Naieni (2005), the reliability of the CTQ was found to be $\alpha=0.86$. Also, it was reported to be a valid (highlighted by the literature), and practical (easy to administer, score, and interpret) measure of critical thinking ability which lets researchers to investigate micro skills of note taking, summarizing, enquiring, rephrasing, investigating, inferencing, debating, categorizing, outlining, comparing and contrasting, distinguishing, synthesizing, inductive and deductive reasoning more effectively. The scores ranged within 30 to 150 . It takes approximately 20 minutes to be completed. Using Cronbach's alpha coefficient, the reliability of critical thinking questionnaire in this study was estimated to be 0.79 . 


\subsubsection{Motivational Strategies Questionnaire}

The English version of Cheng and Dörnyei (2007) motivational strategies questionnaire was used to assess teachers' motivational strategies. This instrument consists of 56 five-point likert scaled items that the participants' scores range from 56 to 280 and it takes about 40 minutes to be completed. validity and reliability of the English version of this questionnaire was examined on a group of 387 Taiwanese teachers. The reliability analysis of the 10 strategy clusters showed that the mean Cronbach Alpha across all the cluster and both scale type was above 0.70. Furthermore, in order to estimate the reliability of this questionnaire in the present study, Cronbach's alpha consistency was run. The reliability of the questionnaire in this study was estimated to be $\alpha=0.71$.

\subsection{Procedure}

The following procedure was followed in order to achieve the purpose of the present study: First, all the participants were informed about the purpose of the study. Then, in another session the motivational strategies questionnaire was given to all the participants that its administration took about 40 minutes. In the next session, the participants were given critical thinking questionnaire, which took about 20 minutes to be completed. It is worth mentioning that the design of the present study was ex post facto (focused-description). In this study, teachers' critical thinking was the predictor variable and the predicted variable was the teachers' use of motivational strategies. Moreover, EFL teachers' teaching experience and age were considered as the control variables of the study. Since the research design selected was a survey study, descriptive statistics was used to describe and summarize the characteristics of data obtained from the groups under study. To determine the degree of relationship between variables, Spearman Rank Order correlation was used.

\section{Results}

The purpose of this study was to determine whether there is any significant relationship between EFL teachers' use of motivational strategies and critical thinking.

\subsection{Descriptive Statistics}

In this part, the descriptive statistics of the results of Peters' Honey critical thinking Questionnaire (2000) as the predictor variable and use of motivational strategies as the predicted variable under investigation would be elaborated.

\subsubsection{Descriptive Statistics of EFL teachers' Critical Thinking}

Given the hypothesis mentioned earlier, the first statistical procedure was to conduct a series of descriptive data analysis on the results of the Peters' Honry Critical thinking questionnaire (CTQ). The maximum score in this test was 150 and as mentioned in the previous chapter, the subjects were 101 EFL teachers who were teaching English as the foreign language in English school in Mashhad.

Upon the administration of the critical thinking questionnaire, the following data in Table 4.1 were obtained.

Table 4.1 Descriptive Statistics of Critical Thinking Questionnaire

\begin{tabular}{|c|c|c|c|c|c|c|c|c|c|}
\hline & $\mathrm{N}$ & Range & Minimum & Maximum & Mean & $\begin{array}{c}\text { Std. } \\
\text { Deviation }\end{array}$ & Variance & \multicolumn{2}{|c|}{ Skewness } \\
\hline & Statistic & Statistic & Statistic & Statistic & Statistic & Statistic & Statistic & Statistic & $\begin{array}{l}\text { Std. } \\
\text { Error }\end{array}$ \\
\hline $\begin{array}{l}\text { Critical } \\
\text { Thinking }\end{array}$ & 101 & 91.00 & 55.00 & 146.00 & 105.5347 & 23.60448 & 557.171 & -.119 & .240 \\
\hline $\begin{array}{l}\text { Valid } N \\
\text { (listwise) }\end{array}$ & 101 & & & & & & & & \\
\hline
\end{tabular}

As can be seen in the above Table, the mean and standard deviation of the 101 participants on the questionnaire equaled 105.5347 and 23.60448 respectively.

\subsubsection{Descriptive Statistics of EFL Teachers' Motivational Strategies}

The other variable in this study was EFL teachers' motivational Strategies. Upon the administration of the motivational strategy use questionnaire, the following data in Table 4.2 were obtained.

Table 4.2 Descriptive Statistics of Motivational Strategy Questionnaire

\begin{tabular}{|c|c|c|c|c|c|c|c|c|c|c|}
\hline & & $\mathrm{N}$ & Range & Minimum & $\begin{array}{l}\text { Maximu } \\
\mathrm{m}\end{array}$ & Mean & $\begin{array}{c}\text { Std. } \\
\text { Deviation } \\
\end{array}$ & Variance & \multicolumn{2}{|c|}{ Skewness } \\
\hline & & Statistic & Statistic & Statistic & Statistic & Statistic & Statistic & Statistic & Statistic & $\begin{array}{r}\text { Std } \\
\text { Error }\end{array}$ \\
\hline $\begin{array}{l}\text { Motivational } \\
\text { Strategy }\end{array}$ & & 101 & 154.00 & 113.00 & 267.00 & 206.0792 & 34.66026 & 1201.334 & -.615 & .240 \\
\hline $\begin{array}{r}\text { Valid } \\
\text { (listwise) }\end{array}$ & $\mathrm{N}$ & 101 & & & & & & & & \\
\hline
\end{tabular}


As can be seen in the above Table, the mean and standard deviation of the 101 participants on the questionnaire equaled 206.07 and 34.66 respectively.

\subsection{Normality Checks}

In order to investigate the normality of the distribution of scores gained on the inventories, the researcher ran normality checks based on the index of the ratio of skewness/std error of skewness. Table 4.3 presents the normality checks.

Table 4.3 Normality Checks

\begin{tabular}{llll}
\hline & \multicolumn{2}{l}{ Skewness } & Skewness/std. Error \\
\cline { 2 - 4 } & Statistic & Std. Error & Ratio \\
\hline Critical Thinking & -.119 & .240 & .495 \\
\hline $\begin{array}{l}\text { Motivational } \\
\text { Strategy }\end{array}$ & -.615 & .240 & 2.562 \\
\hline
\end{tabular}

The indices in Table 4.3 clarify the normality of the distribution of scores in critical thinking. However, the motivational strategy scores were not normally distributes as the skewness/std error of skewness ration exceeded the range of -1.96-1.96. Figures 4.1-4.2 illustrate the distribution of scores on the questionnaires.

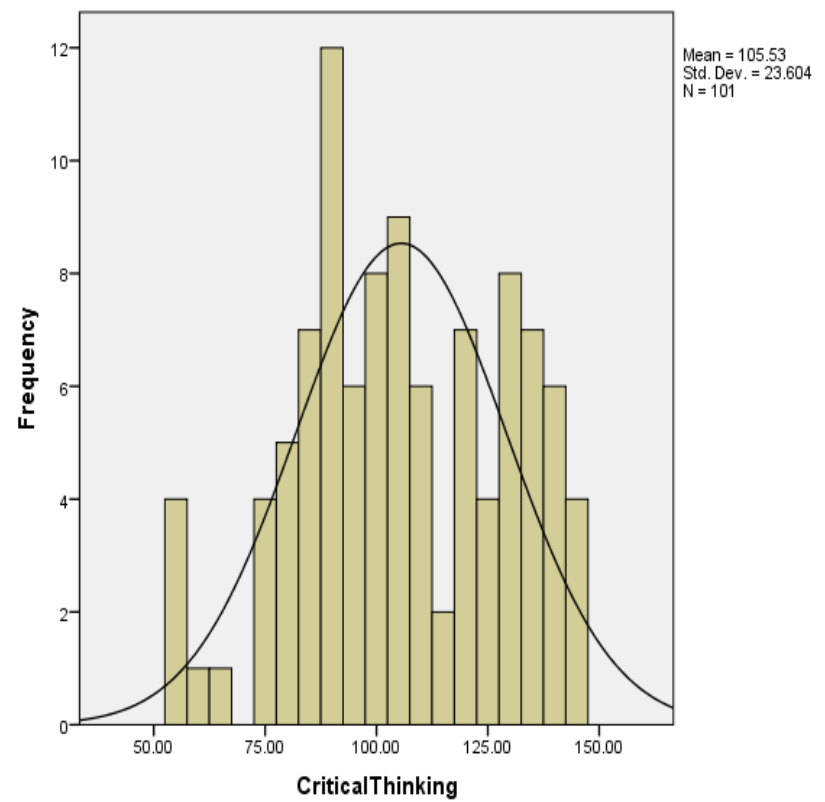

Figure 4.1 Distribution of Scores of Critical Thinking Questionnaire

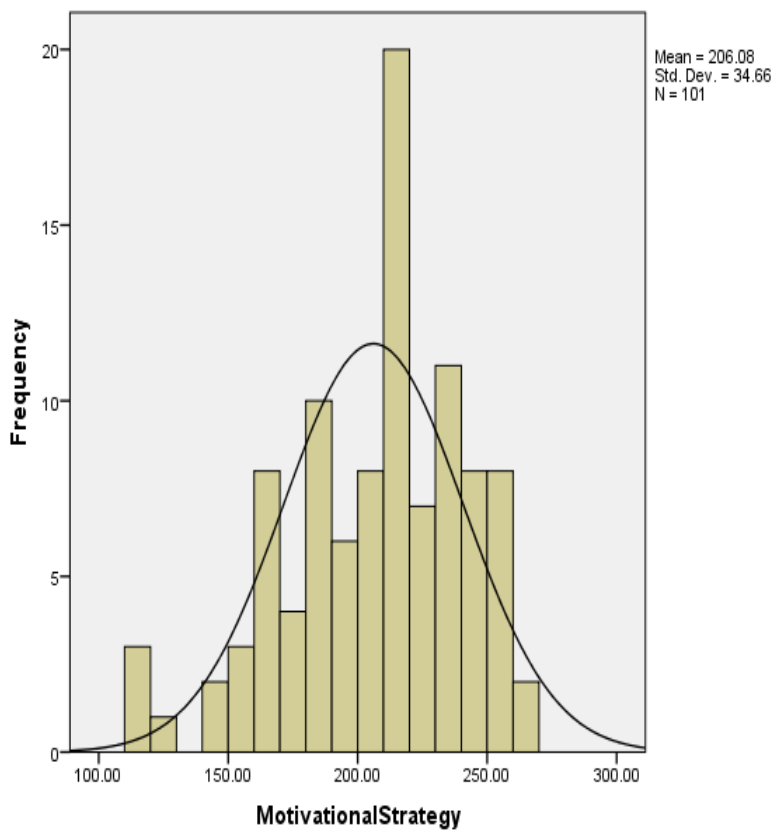

Figure 4.2 Distribution of Scores of Motivational Strategy Questionnaire 


\subsection{Testing the Null Hypothesis}

Considering the fact that one of the distributions of scores did not show normalcy the researcher had to run a nonparametric inferential statistical analysis, namely Spearman Rank Order correlational statistics. The details are demonstrated in Table 4.4.

Table 4.4 Correlations

\begin{tabular}{|c|c|c|c|c|}
\hline & & & $\begin{array}{l}\text { Critical } \\
\text { Thinking }\end{array}$ & $\begin{array}{l}\text { Motivational } \\
\text { Strategy }\end{array}$ \\
\hline \multirow[t]{6}{*}{ Spearman's rho } & Critical Thinking & $\begin{array}{l}\text { Correlation } \\
\text { Coefficient }\end{array}$ & 1.000 & .182 \\
\hline & & Sig. (2-tailed) & . & .069 \\
\hline & & $\mathrm{N}$ & 101 & 101 \\
\hline & $\begin{array}{l}\text { Motivational } \\
\text { Strategy }\end{array}$ & $\begin{array}{l}\text { Correlation } \\
\text { Coefficient }\end{array}$ & .182 & 1.000 \\
\hline & & Sig. (2-tailed) & .069 & . \\
\hline & & $\mathrm{N}$ & 101 & 101 \\
\hline
\end{tabular}

The data in the Table above shows that there is no correlation between critical thinking and motivational strategy. As the result of study demonstrated there is no correlation between critical thinking and motivational strategy. Therefore; critical thinking is not making a significant contribution to the prediction of motivational strategies. It means that effective EFL teachers at English schools are not the ones who have benefited from critical thinking.

\section{Discussion}

This study investigated the relationship between EFL teachers' use of motivational strategies and critical thinking. The findings showed that the relationship between motivational strategies and critical thinking was non-significant.

Based on the researcher's knowledge and experience, both as learner and teacher, at the beginning levels of education, Iranian students might be involved in critical thinking to some extent, but in higher levels, they are not encouraged to think critically. That is in the context of Iran, teachers do not have any courses concerning critical thinking to improve this ability at schools and universities. The researcher believes that this, in turn, is due to the wider socio-cultural context in which obedience is encouraged and any tendency toward critical thinking are suppressed. It is not possible to deny that culture of education and culture of society are interdependent. In societies such as Iran, the teachers are not allowed to criticize and express their opinions freely.

The findings of the present study are not in line with those of a number of previous studies (e.g., Kamali \& Fahim, 2011; Mirzai, 2008; Sheikhi, 2009), which indicted there existed a significant positive relationship between teachers' critical thinking and their use of motivational strategies. However, as pointed earlier, the result of this study showed that there was no significant relationship between EFL teachers' critical thinking and their use of motivational strategies. The differences between the findings of the present study and those of other studies can be counted to the cultural differences leading to different abilities of the participants. Volet (1999 cited in Lun et al, ibid) sustains that different academic contexts have their own unique culture of learning. The Iranian context falls into the same classification.

\section{Conclusion and Implications}

The objective of the study was to investigate the relationship between EFL teachers' critical thinking and their use of motivational strategies. The key results of the data analysis showed that there was no correlation between critical thinking and motivational strategy. Therefore; critical thinking is not making a significant contribution to the prediction of motivational strategies.

Critical thinking and use of motivational strategies, as a cognitive factors, play a crucial role in decision-making and problem-solving process (Jay \& Johnson, 2002), thus, these two teacher-related features encourage teachers to supply effective teaching and create a meaningful learning environment while they effectively shape the processes of making decisions and planning work for students. Consequently, stakeholders in education need to take strong measure to help teachers increase their motivational strategy and critical thinking. Mainly, colleges and universities have to have quality educators, who could teach courses that assist critical thinking skills for teacher candidates as they will need such skills in real -world situations. For the teachers in the area, school locality should provide professional development, trainings, and seminars on motivational strategy and critical thinking.

The findings of study have some implications for EFL teachers, practitioners and curriculum and material developers. Although the present study showed that there was no significant relationship between critical thinking and use of motivational strategies, EFL teachers should become aware that being critical thinkers will help them become more flexible, reflective and effective teachers and this can display on their students as well. As pointed out by Ennis (1986), critical thinking helps teachers to develop and organize their thoughts in the process of their L2 teaching and learning.

Though no significant relationship was found between the aforementioned variables, based on the extensive review of the related literature it can be stated that in order to make teachers' critical thinking and use of motivational strategies 
indispensable constructs in teacher education, it seems obligatory to equip instructors and teachers with teacher preparation programs mainly focused on nurturing the abilities and insights of teachers with lower level of critical thinking and rarely users of motivational strategies, to merit exponential achievement and success and consequently greater learner contentment with instructors in specific and the educational system in general. It is noteworthy that all detections and deductions were based on self-reporting by the participants, therefore, were prone to the inherent limitations of self-reporting and the teachers' ethnic background in using motivational strategies which have not been confirmed before.

Since this study made use of only self-report instruments, the future studies can utilize other ways of data collection such as interviews and observations. Furthermore, as this study was directed only in private language schools, further research is needed to be accomplished at high schools in order to compare the results. Other researchers can appeal the research for different ages and proficiency levels of students. Finally, further research is deemed necessity to examine the type of motivational strategies applied Iranian EFL teachers.

\section{Acknowledgment}

This paper is based on the author's MA thesis. The author would like to thank Islamic Azad University, Central branch, Tehran, Iran.

\section{References}

Alison, J., \& Halliwell, S. (2002). Challenging classes: Focus on pupil behavior. London, Great Britain: CILT.

Al-Mahrooqi, R., Abrar-ul-Hassan, S. \& Asante, C. (2012). Analyzing the use of motivational strategies by EFL teachers in Oman. Malaysian Journal of ELT Research, 8(1), 36-76.

Astleitner, H. (2007). Teaching critical thinking online. Journal of Instructional Psychology, 29(2), 53-77

Brown, H. D. (2001). Teaching by Principles (2 ${ }^{\text {nd }}$ ed.). New York: Longman.

Chambers, G. N. (1999). Motivating language learners. Clevedon, U.K.: Multilingual Matters.

Cheng, H.-f., and Dörnyei, Z. (2007). The use of motivational strategies in language instruction: The case of EFL teaching in Taiwan. Innovation in Language Learning and Teaching 1, 153-174.

Cottrell, S. (2005). Critical thinking skills. Developing effective analysis and argument. New York: Palgrave Macmillan.

Dornyei, Z. (2001). Motivational strategies in the language classroom. Cambridge. University Press.

Dornyei, Z., (2010). Researching motivation: From integrativeness to the ideal L2 self. Introducing applied linguistics: Concepts and skills, 3(5) 74-83.

Dornyei, Z., \& Csizer, K. (1998). Ten commandments for motivating language learners: Results of an empirical study. Language teaching research, 2(3), 203-229.

Dörnyei, Z, \& Otto, I. (1998). Motivation in action: A process model of L2 motivation. Working Papers in Applied Linguistics (Thames Valley University, London), 4, 43-69.

Ellis, R. (1997). Second language acquisition. Oxford: Oxford University Press.

Ennis, R. (1986). A taxonomy of critical thinking dispositions and abilities: teaching thinking skills theory and practice. New York: W.H. Freeman and Company.

Ennis, R. (1996). Critical thinking assessment. Theory into Practice, 32(3), 179-186.

Facione, P. A. (2000). The disposition toward critical thinking: Its character, measurement, and relation to critical thinking skill. Informal Logic, 20(1), 61-84.

Glaser, E. (1942). An experiment in the development of critical thinking. The Teachers College Record, 43(5), 409-410.

Huangfu, W. (2012). Effects of EFL teachers' self-efficacy on motivational teaching behaviors. Asian Social Science, 8 , $15,68-74$.

Jay, J. K., \& Johnson, K. L. (2002). Capturing complexity: a typology of reflective practice for teacher education. Teaching and Teacher Education, 18, 73-85.

Kadir, M. A. A. (2007). Critical thinking: A family resemblance in conceptions. Journal of Education and Human Development, 1(2), 1-11.

Kamali, Z., \& Fahim, M. (2011). The relationship critical thinking ability of Iranian EFL learners and their resilience level facing unfamiliar vocabulary items in reading. Journal of Language Teaching and Research, 2(1), 104-111.

King, A. (1995). Designing the instructional process to enhance critical thinking across the curriculum. Teaching of Psychology, 22(1), 13-17.

Kurffiss, J. G. (1988). Critical Thinking: Theory, Research, Practice, and Possibilities. ASHE-ERIC Higher Education Report No. 2, 1988. ASHE-ERIC Higher Education Reports, The George Washington University, One Dupont Circle, Suite 630, Dept. RC, Washington, DC 20036-1183. 
McDonough, S. (2007). Motivation in ELT. ELT Journal, 61, 369-371.

Mason, M. (2007). Critical thinking and learning. Educational Philosophy and Theory, 39(4), 337-473.

Marzano, R, Pickering. D., \& Pollack, J. (2001). Classroom instruction that works. Alexandria, VA: Association for Supervision and Curriculum Development.

Mirzai, Z. (2008). The relationship between critical thinking and lexical inferencing of Iranian EFL learners. Unpublished master's thesis, Azad University of Science and Research, Tehran, Iran.

Noddlings, N. (2006). Critical lessons. What our schools might teach but do not. New York: Cambridge. Paul, R., \& Elder, L. (2002). Critical thinking: tools for taking charge of your professional and personal life. Dillon Beach, CA: Foundation for Critical Thinking.

Norris, S. P., \& Ennis, R. H. (1989). Evaluating Critical Thinking. The Practitioners' Guide to Teaching Thinking Series. Critical Thinking Press and Software, Box 448, Pacific Grove, CA 93950-0448.

Paul, R. W. (1992). Critical thinking: What, why, and how? New Directions for Community Colleges, 77, 3-24.

Paul, R., \& Elder, L. (2005). A guide for educators to critical thinking competency standards. Dillon Beach, CA: Foundation for critical thinking.

Paul, R., Elder, L., \& Bartell, T. (1997). California teacher preparation for instruction in critical thinking: research findings and policy recommendations. Sacramento, CA: California Commission on Teacher Credentialing.

Sheikhi, B. R. (2009). The relationship between Autonomy, Critical thinking and Reading comprehension of Iranian EFL learners. Unpublished masters, Azad University of Science and Research, Tehran, Iran.

Solak, E., \& Bayar, A. (2014). The factors influencing the motivational strategy use of non-native English teachers. International Journal of Education and Research, 2(2), 1-12.

Takeuchi, O., \& Sugita, M. (2010). What can teachers do to motivate their students? A classroom research on motivational strategy use in the Japanese EFL context. Innovation in Language Learning and Teaching, 4(1), 21-35.

Ushioda, E. (2011). Language learning motivation, self and identity: Current theoretical perspectives. Computer Assisted Language Learning, 24(3), 199-210.

Williams, M., \& Burden, R. L. (1997). Psychology for language teachers: a social constructivist approach. Cambridge: CUP. 